\title{
A Study on the Characteristics of Microseismic Signal during Deformation and Failure of Different Materials under Uniaxial Compression
}

\author{
Chengwu Li, ${ }^{1}$ Xiaomeng Xu, ${ }^{1,2}$ Lihui Dong, \\ Mohammad Sarmadivaleh, ${ }^{2}$ and Xiaoyuan Sun ${ }^{1,3}$ \\ ${ }^{1}$ Faculty of Resources and Safety Engineering, China University of Mining and Technology, Beijing 100083, China \\ ${ }^{2}$ Department of Petroleum Engineering, Curtin University of Technology, Perth, WA 6151, Australia \\ ${ }^{3}$ School of Safety and Environment, Taiyuan University of Science and Technology, Taiyuan 030024, China \\ Correspondence should be addressed to Xiaomeng Xu; xxmsafety@163.com
}

Received 5 June 2015; Revised 5 October 2015; Accepted 8 October 2015

Academic Editor: José A. Becerra Villanueva

Copyright (C) 2016 Chengwu Li et al. This is an open access article distributed under the Creative Commons Attribution License, which permits unrestricted use, distribution, and reproduction in any medium, provided the original work is properly cited.

\begin{abstract}
With the decline of shallow coal reserves and increase in demand of coal consumption, the hazard of coal and rock dynamic disasters is expanding. In this paper, we conducted some laboratory scale tests on coal, cement, and glass materials to figure out the microseismic (MS) characteristic differences among materials. A new method, denoted as WPT-LMD, is proposed to conduct signal denoising and analysis work. A series of basic analyses regarding MS are conducted, including the relationships between MS characteristics and loading rate, coal powder particle size, loading stage, and MS event statistics. Research results show that the damage of all these three materials is accompanied with MS events, abundant with low frequency component $(0-200 \mathrm{~Hz})$. But cement and coal specimens produce with relative wide frequency distribution in sample frequency domain, while glass specimens were found to only produce low frequency event. The powder particle sizes have obvious influence on the strength of coal specimen, but the loading rate seems to have no influence on the MS characteristics. The outcome of the paper will further provide a theoretical basis for understanding the mechanism of MS activities and has great significance to improve the coal mining safety.
\end{abstract}

\section{Introduction}

It is generally known that many solid materials emit low-level seismic signals during their deformation and damage process, and this phenomenon is generally called acoustic emission $(\mathrm{AE})$ at the laboratory specimen scale or microseismicity (MS) at the rock massive scale (denoted as MS in this work for unity) $[1,2]$. In the coal mining industry, microseismic monitoring techniques are usually utilized in detecting the fracture and failure of large area of rocks and finally realizing the forecast and prevention of dynamic disasters (rock burst and coal and gas outburst) [3]. As a result, most deep coal mines in China have installed MS monitoring system to observe the abnormal microseismic activities during the blasting, tunneling, drilling, top coal caving, and excavating process $[4,5]$. It is proved that MS technique is a novel tool to be used as a remote proxy for daily safety monitoring at rock burst-prone mines. But, in recent years, there are still nearly 200 causalities caused by dynamic disasters every year in the coal mining industry of China [6]. That is to say, there is still an urgency to figure out how to use MS more efficiently and realize accurate real-time prealarming for dynamic disasters.

Many research studies have been conducted on both the mechanism and characteristics analysis of microseismic activities. Cook put forward utilizing MS technique to solve the rock burst problems and in his following works he tried to figure out the mechanism of MS [7-9]. Yamada et al. studied the relationship between AE/MS event counts and sample damage during the loading process of coal and rock [10]. $\mathrm{Lu}$ and some other researchers conducted a series laboratory modeling work to simulate the field site rock burst forecasting with MS $[3,4]$. The relationship between frequency-spectrum characteristics of MS events and the damage evolution law of material during the uniaxial and triaxial compression loading 
were also studied in the laboratory test scale $[11,12]$. However, the comparison of characteristics of MS events between different materials is merely considered and represented in studies above. But this is very important for improving the accuracy of prealarming work underground. This is mainly because the coal seam has great differences with its surrounding rocks, and, due to the diversity of mechanic properties, the roof, floor rocks, and coal seam may generate quite different patterns of seismicity [3].

To study the MS characteristics of different materials, we choose the cement paste, coal, and glass to make specimens and perform some uniaxial compression loading on these samples, and this kind of test was rarely found in the previous studies. There are several considerations for our decisions of using these three materials. Actually, we selected them mainly for their distinguished mechanic properties. Glass is selected for it is a type of typical brittle material; it will be fractured directly under critical stress, so here it is used to present the extremely brittle rocks [13]. Coal is also kind of brittle rock but previous studies showed that coal would experience a process of compaction before showing its linear elastic feature, and only after reaching the strain-soft stages did the primary damage begin [3]. The artificial briquette specimen will be slightly different to natural coal bulks, for it is more homogeneous and isotropic, but the main loading patterns are the same as natural bulks. Cement paste specimens are widely used in the research studies of construction and civil engineering issues; the selection of cement paste means we have more standard references and results to be compared. Also, in the underground field site, there are many artificial constructions with concrete and cement; these nonnatural structures will also produce some MS signal which may affect the accuracy of MS monitoring. In summary, we believe that these three kinds of material should be well represented for different material properties.

This paper mainly conducts experiment studies on material deformation damage and AE/MS feature under uniaxial loading circumstance. A new method by combining the wavelet packet transform (WPT) and local mean decomposition (LMD) is proposed to denoise and analyze MS signal. On the basis of the application of the WPT-LMD method, the characteristics of MS signal produced by the deformation and damage of coal, cement, and glass samples are compared and analyzed. The remainder of this paper is summarized as follows. Section 2 describes the theory and application procedure of WPT-LMD method. In Section 3, the details of sample preparation and the procedure of laboratory test are presented. In Section 4, the experiment results of several typical tests of different materials are illustrated. Discussions for the effects of material type, loading rate, and coal particle size on MS characteristics and MS event parameters statistics are given in Section 5. Conclusion and future work are presented in Section 6.

\section{MS Signal Processing Method}

2.1. Combination of WPT and LMD. A basic analysis on the laboratory test data shows that the original signal is partially swamped by the ambient noises. Moreover, the dominant frequency distribution range of MS signals here was relatively wide; both low frequency $(<100 \mathrm{~Hz})$ and high frequency $(500-1500 \mathrm{~Hz})$ compositions exist in the whole effective sample frequency domain. Consequently, it becomes hard to separate the real event signals from background noises by using sets of filters normally as used in the previous studies, such as some moving average filter, Wiener filter, or low-pass filter based on Fourier transform [14-17]. So we developed a new method in this work, which is actually the combination of wavelet packet transform (WPT) and local mean decomposition (LMD). This method is denoted as WPT-LMD method here and it is selected to perform signal denoising and analyzing throughout this work. The principle and algorithm of WPT have been widely discussed and presented in a lot of literatures $[18,19]$. To be simple, only the information of LMD is briefly described here, but the details of its theory and algorithm could be found somewhere else $[17,20]$.

Local mean decomposition, firstly proposed in 2005, is a new adaptive time-frequency analysis method [17]. It is famous for its good performances in dealing with nonlinear and nonstationary signals. The basic algorithm of LMD is very similar to empirical mode decomposition (EMD), which is developed earlier and widely applied in various studies. But several investigations conclude that LMD is better than EMD in signal processing, especially for solving the endpoint effect and avoiding the mode mixing problems $[20,21]$. LMD decomposes signal into a set of product functions (PFs), which represents characteristics of frequency band and energy distribution $[17,20]$. Dealing with the PFs, it is easy to deny or filter the signal, calculate instantaneous frequency (IF), and reconstruct reserved PFs into a new signal. Based on both the algorithms of WPT and LMD, we successfully actualized the data processing with WPT-LMD method, and all coding works were conducted with MATLAB software.

2.2. MS Signal Processing Procedure. To start with, WPT method is firstly adopted to conduct a soft threshold global denoising and then the denoised data are decomposed to find the best tree structure (level 5) [19]. The best tree nodes of a coal specimen (CSA2) are shown in Figure 1. To find the best mother wavelet, a denoising effect comparison among db5, $\mathrm{db} 8$, and sym6 wavelet function is made and finally $\mathrm{db} 8$ is chosen.

In the following process, LMD method is performed on the decomposition signal of each tree node and a series of PFs for every node are obtained. Some PFs that mainly contain environment noises will be determined as ineffective decomposition and removed, while others will be judged as effective PFs and reserved. To determine whether a PF is an effective signal or noise decomposition, the concept of contribution coefficient is introduced. The definition of contribution coefficient is shown in

$$
c_{i}=\frac{\left|r_{i}\right| \cdot e_{i}}{\sum_{i=1}^{n}\left|r_{i}\right| \cdot e_{i}},
$$



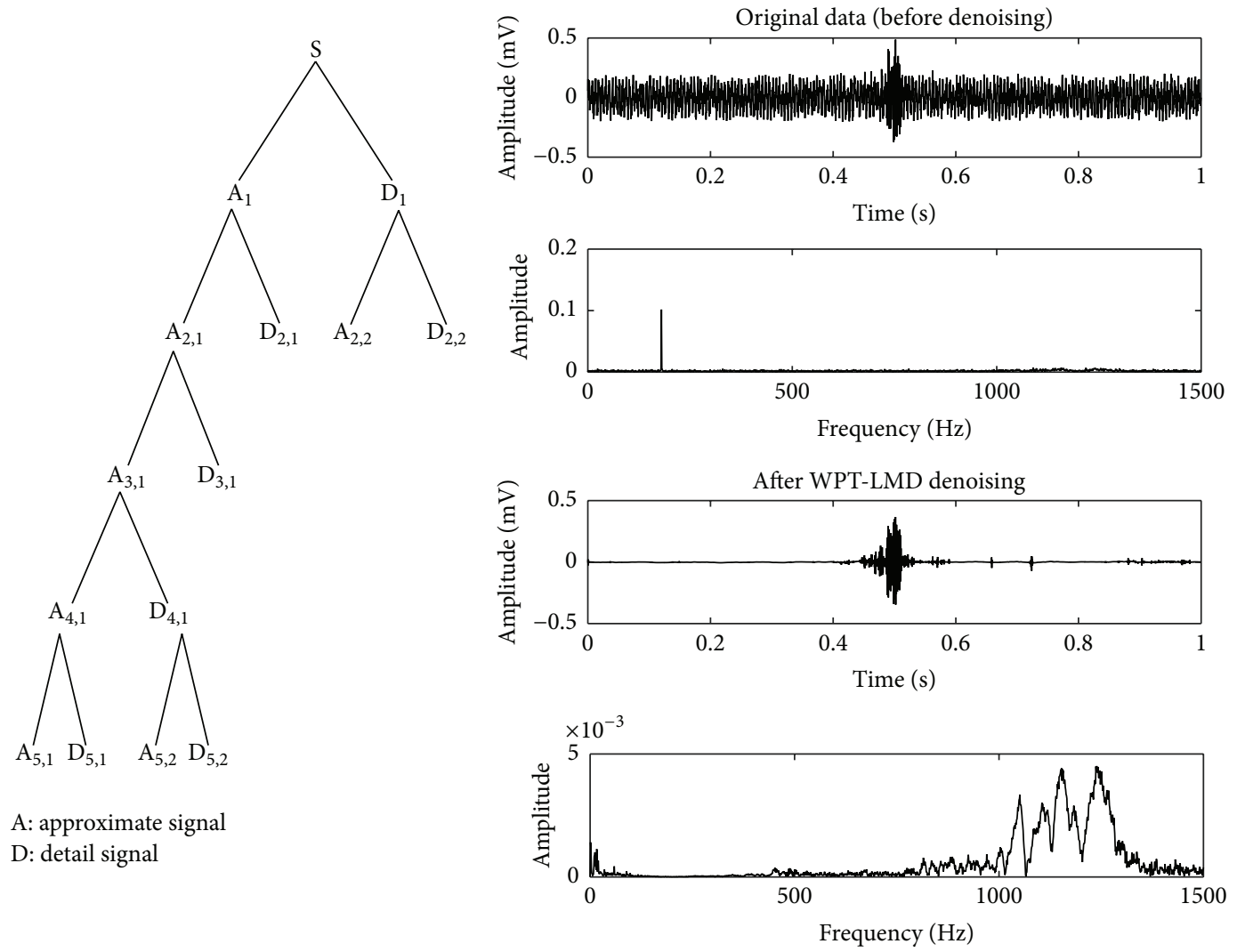

FIGURE 1: The WPT best tree of CSA2 and denoising effect of WPT-LMD method.

where $c_{i}$ is referred to as the $i$ th contribution coefficient, $i$ is the number of PFs, $n$ is the total number of PFs, $r_{i}$ is the correlation coefficient between $i$ th PF and original signal, and $e_{i}$ is the occupation ratio of energy of $i$ th PF; only when $c_{i}$ is larger than the critical value 0.001 the $\mathrm{PF}$ is selected as effective decomposition.

All effective PFs preserved are combined to reconstruct the new tree nodes and then all nodes are reconstructed and got the denoised signal series. A comparison between the original signal and denoised signal is also shown in Figure 1.

Finally, LMD method is used again on the denoised signal. Some basic analysis could be easily done with the final $\mathrm{PFs}$, such as the characteristics of frequency spectrum of the whole signal or the features of the energy distribution and instantaneous frequency of each PF.

\section{Experimental Setup}

3.1. Experimental Equipment and Characteristic Parameter. The experimental testing system was comprised of stress loading equipment and data acquisition apparatus. As shown in Figure 2, the EHF-UG500KN type servo press machine (Shimadzu Corp., Japan) was used to provide the uniaxial compressive loading environment. While the coal and rock dynamic disaster monitoring system (ZDKT-1, CUMTB2009) was served as seismic activities monitoring facilities and data acquisition module in this work. ZDKT-1 is a real-time monitoring system developed for the forecast of coal and rock dynamic disasters in a coal mining field site. This system is multichannel and multiparameter monitoring system, and it can also be used in the laboratory test. Electromagnetic, geomagnetic, and microseismic transducers, stress and strain gauges, and gas concentration sensors are all included in the whole system. It totally has 12 channels, with a $51 \mathrm{kHz}$ maximum data sample rate. In this work, the sample rate was set as $3000 \mathrm{~Hz}$, to digitize, filter, and store data automatically.

To describe characteristics of MS signal, several basic parameters for both process parameters and state parameters are included in this work. These parameters are amplitude, frequency, MS event counts and event rate, energy accumulation, and energy release rate. Actually, all these parameters are commonly used in the traditional MS/AE studies and their basic definition could be found somewhere else [2]. To get the values of these parameters, the STA/LTA (short/long term average) method was used to recognize the MS signal [22]. Then, every individual MS event detected was extracted from the total data and this will be used for further quantitative analysis on characteristic parameters. We have set the STA and LTA energy window lengths at $10 \mathrm{~ms}$ and $200 \mathrm{~ms}$, respectively. As the sample rate is $3000 \mathrm{~Hz}$, the short series number should be 30 and long series number is 600 , and the trigger threshold value for STA and LTA ratio is selected as 5 . 


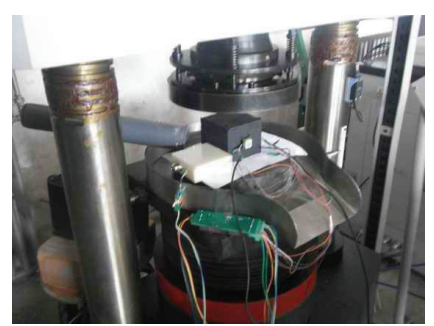

(a)

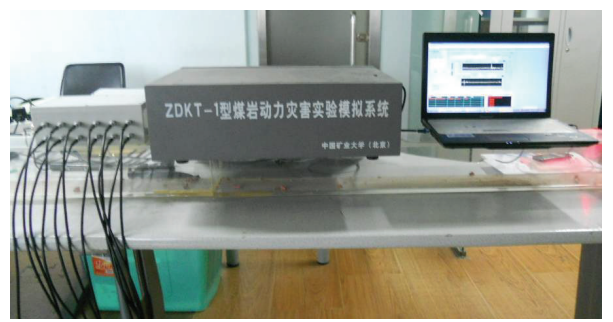

(b)

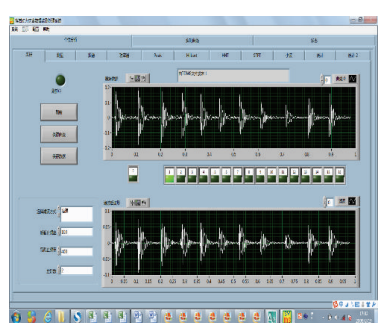

(c)

FIGURE 2: Testing system (a) loading equipment; (b) ZDKT-1 dynamic disaster monitoring system; (c) data acquisition software.
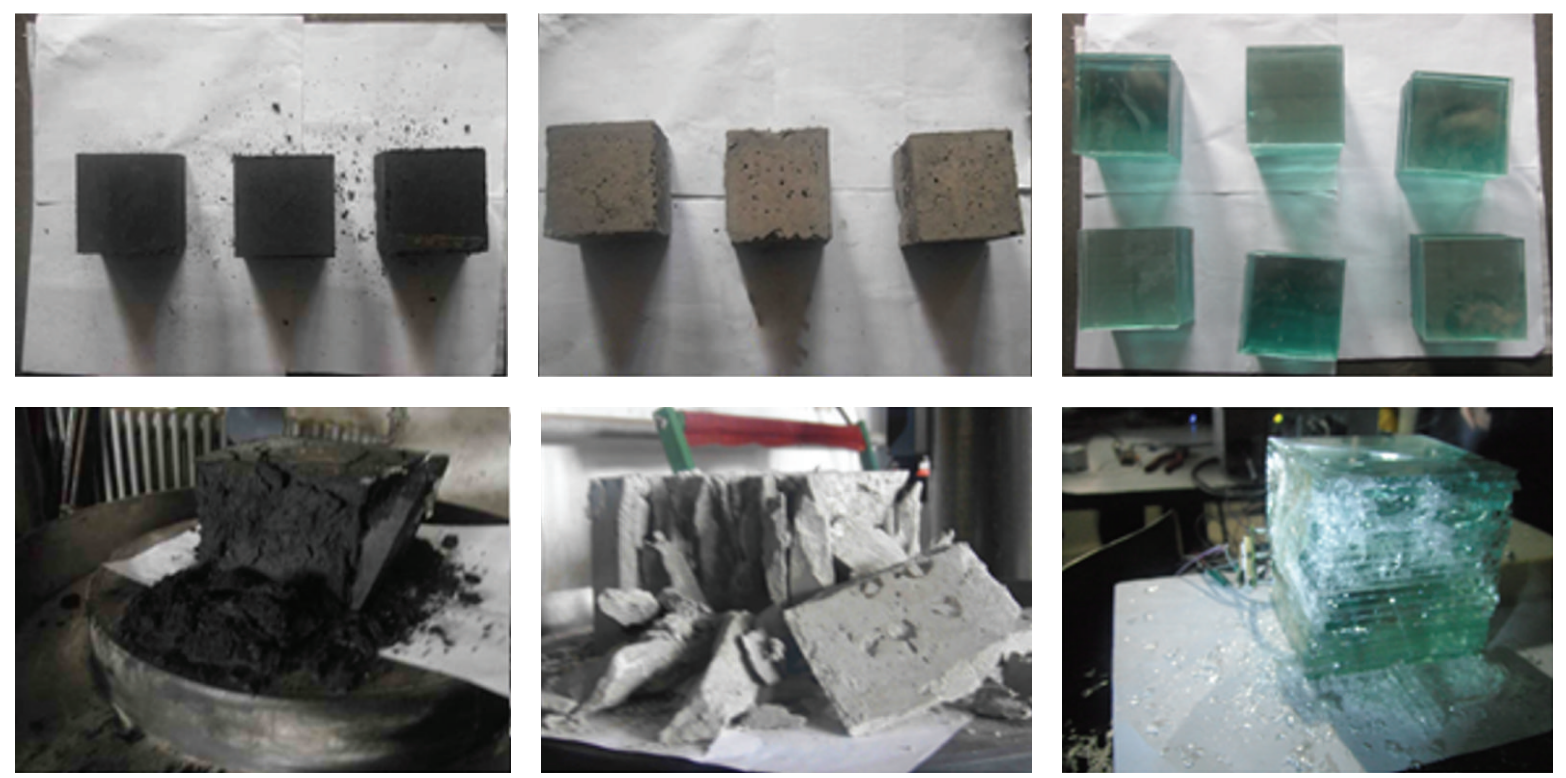

FIGURE 3: Original and damaged patterns of different types of specimens.

3.2. Specimen Preparation. Three types of specimens made by different materials were tested in uniaxial compression: briquette coal specimens, cement specimens (pure Portland cement), and glass specimens. The original and damaged patterns of all these three types of specimens are shown in Figure 3.

Coal blocks were gathered from Pingdingshan $10^{\#}$ coal colliery, where strong dynamic disasters often occurred. These coal bulks are crushed and sieved into $0.5 \mathrm{~mm}-2 \mathrm{~mm}$, $0.25-0.5 \mathrm{~mm}$, and less than $0.25 \mathrm{~mm}$ particle powder in diameter. After that, some water and coal tar were mixed into coal powder, and the proportion by weight is $0.5: 1: 20$ (water: coal tar: coal powder). Then, the mixed powder was cast in the steel molds and stressed under $10 \mathrm{MPa}$ axial pressure. A small amount of wax was attached to the internal surface of the mold before making every specimen, to get out the shaped briquette sample easily. To keep the good mechanical consistency between these artificial samples, several measures were adopted: (1) all specimens were made with the same size mold $(100 \times 100 \times 100)$ and the qualities of coal powder and coal tar were strictly controlled. (2) All specimens were kept stressed under $10 \mathrm{MPa}$ axial loading pressure for up to 8 hours. (3) The specimens were removed from the molds 24 hours after unloading the stress and cured for 28 days in a curing room. Totally, there were 9 briquette specimens made, 3 for each particle size.

In contrast, two kinds of cement, Portland 42.5 and $42.5 \mathrm{R}$ types, were selected to make cement specimens. The whole process of making cement specimen is similar to that of coal, but the mix proportion for cement paste by weight is $0.35: 1$ (water : cement). Also, there was no external loading conducted when making this kind of specimens. These specimens were removed from the mold after casting and cured for 28 days at $20 \pm 2^{\circ} \mathrm{C}$. Glass specimens were made by gluing 20 layers of glass together with glass cement, with $5 \mathrm{~mm}$ thickness for each piece. Still, for cement and glass specimens, there were 3 prepared for each type and they were all in the same size of $100 \times 100 \times 100 \mathrm{~mm}$ in cubic shape.

3.3. Test Procedure. The whole experiment process consisted of the following steps:

(1) Place the specimens on the centre of the platform of testing machine and attach microseismic transducer to the surface of specimen. 
TABLE 1: Experimental parameters of specimens and work condition details.

\begin{tabular}{|c|c|c|c|c|c|}
\hline Specimen number & Loading rate $(\mathrm{N} / \mathrm{s})$ & Peak value $(\mathrm{kN})$ & Loading time (s) & \multicolumn{2}{|c|}{ Special note } \\
\hline CSA2 & 10 & 7.74 & 1050 & Particle size & $<0.25 \mathrm{~mm}$ \\
\hline CSB1 & 5 & 2.24 & 270 & Particle size & $0.25-0.50 \mathrm{~mm}$ \\
\hline CSB2 & 10 & 2.72 & 150 & Particle size & $0.25-0.50 \mathrm{~mm}$ \\
\hline CSB3 & 20 & 10.7 & 1830 & Particle size & $0.25-0.50 \mathrm{~mm}$ \\
\hline CSC2 & 10 & 3.18 & 300 & Particle size & $0.50-2.00 \mathrm{~mm}$ \\
\hline CMSA1 & 150 & 123.22 & 910 & Cement type & P.O. 42.5 \\
\hline CMSA2 & 200 & 162.96 & 860 & Cement type & P.O. 425 \\
\hline CMSA3 & 250 & 196.59 & 820 & Cement type & P.O. 425 \\
\hline GSB1 & 200 & 296.3 & 1610 & Layer count & 10 \\
\hline GSB2 & 250 & 204.48 & 870 & Layer count & 10 \\
\hline GSB3 & 300 & 479.3 & 1630 & Layer count & 10 \\
\hline
\end{tabular}

(2) Turn on the ZDKT-1 type dynamic disaster monitor apparatus, start up the monitoring operation system, and set related initial parameters well, for example, the loading rate, sample frequency, and initial loading force.

(3) Before recording the data, verify that signal acquisition module worked well and begin to record data.

(4) Start the loading process and keep loading until the specimens were completely damaged.

(5) Stop loading and recording; save the data file.

(6) Repeat the procedure again and run test on other specimens.

\section{Experimental Result and Analysis}

A series of uniaxial compression loading were conducted on coal, cement, and glass specimens. The detailed experimental parameters, such as the loading rate, loading last time, and the peak value of loading force, are shown in Table 1. Due to the space limitation, only partial results of the tests for each kind of specimen are presented in this paper. To be more specific, they are actual 5 tests of coal specimens, 3 tests of cement, and 3 tests of glass. But that is still enough to show the characteristics changes of MS signal under various loading conditions. For instance, CSB1, CSB2, and CSB3 are used for discussion on MS feature changes with the variation of the loading rate; CSA2, CSB2, and CSC2 are selected to give a comparison between samples made by different particle size of coal powders; and of course MS data recorded from different materials are mainly used to compare the characteristics of MS events from each other.

The material failure process is accompanied by MS/AE, which is actually a form of quick release of stored energy. Specimens here were investigated for their mechanical performances with microseismicity patterns throughout the whole loading process. Theoretically speaking, the continuous loading on material will cause the accumulation of strain energy inside; once the accumulated energy exceeds the ultimate value limited by the mechanical properties of materials, internal fracture generation and external damage will occur.
Generally, there are five detailed stages of the damage and deformation of materials under uniaxial compression, that is, crack closure, crack initiation, secondary cracking, crack coalescence, and crack damage [23]. However, the actual stress loading patterns will be affected a lot due to the mechanical properties of materials. The MS activities and loading stress variations with the loading time increase are illustrated in Figure 4. To make it easier to be analyzed, each test was divided into 10 loading sections according to total loading time. We defined sections I-III as early stage, sections IV-VII as middle stage, and sections VIII-X as poststage.

In case of coal specimens, MS activities occurred at both early stage and poststage, but the primary fracture period of coal occurred in the poststage. As illustrated in Figure 4, at early loading stage of coal samples, there were several MS activities produced; after that, before the peak of loading stress, only few MS activities could be observed; most of the MS events were collected after the loading peak value. These briquette coal specimens mostly were destroyed under stress less than $10 \mathrm{KN}$ and produce MS signals with lowest amplitude for $15 \mathrm{mV}$ in comparison with cement and glass specimens. The patterns of MS events for cement samples are very similar to coal; most activities are collected in primary fracture and early stage, but it should be noticed in the middle of loading, just before the main fracture happens, that the MS release is also very active. With respect to event rate, the values for cement samples are lowest in all three materials. For the glass samples, due to their larger uniaxial strength and layer distribution, more MS activities are found through the whole loading process. Loading on glass samples obtained the largest loading stress and the highest MS amplitude, ranging from $250 \mathrm{kN}$ to $300 \mathrm{kN}$ and approximately $100 \mathrm{mV}$, respectively; the same value to cement specimen is ranging from $150 \mathrm{kN}$ to $200 \mathrm{kN}$ and $60 \mathrm{mV}$.

The LMD result of CSC2 is shown in Figure 5. The denoised signal, which is obtained by filtering the original signal, is decomposed into several PFs. These PFs have different characteristics in both frequency and time domain. The frequency distributions are separated into three series. The high frequency is all collected at the early stage and main fracture stage with highest amplitude, and the frequency is about $1000-1200 \mathrm{~Hz}$. The medium frequency is the second 

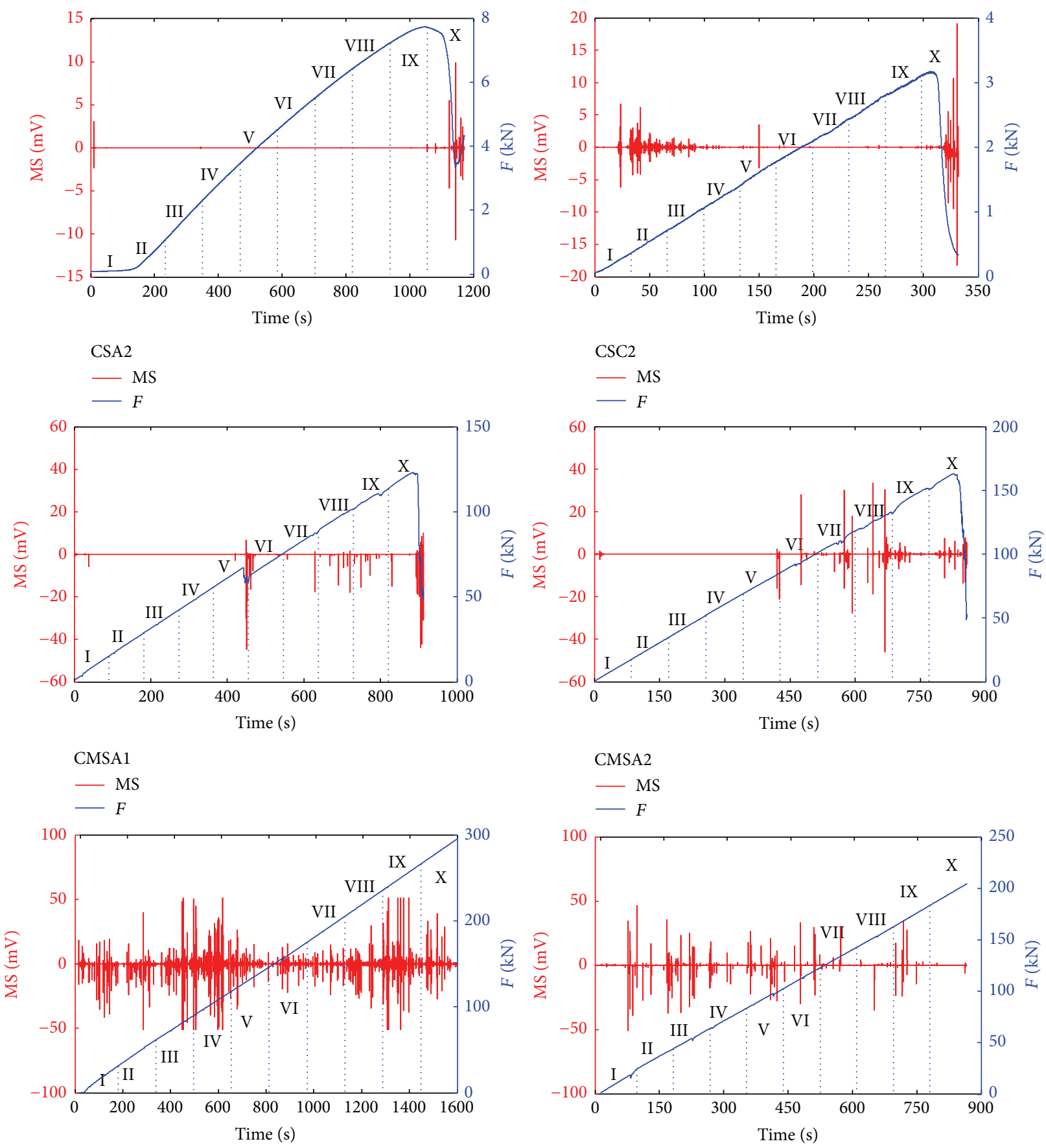

GSB1

- MS

GSB2

MS

Figure 4: The MS events signal with increase of loading stress and time.

most abundant with MS events; its frequency ranges from 100 to $500 \mathrm{~Hz}$. Low frequency decomposition owns low amplitude, but it should not be overlooked, for low frequency signal (lower than $100 \mathrm{~Hz}$ ) usually spread further in real practice. As its illustration of the whole loading process, it seems that there are not too many events that could be found in the figure. The detailed characteristics will be shown in the following part.

\section{Discussion}

5.1. Spectrum Characteristics in Different Loading Stages. As stated above, every test is divided into three stages and ten sections. To analyze the characteristics of different materials in different loading stages, typical microseismic events from each stage are selected. Figure 6 illustrates diagrammatically 

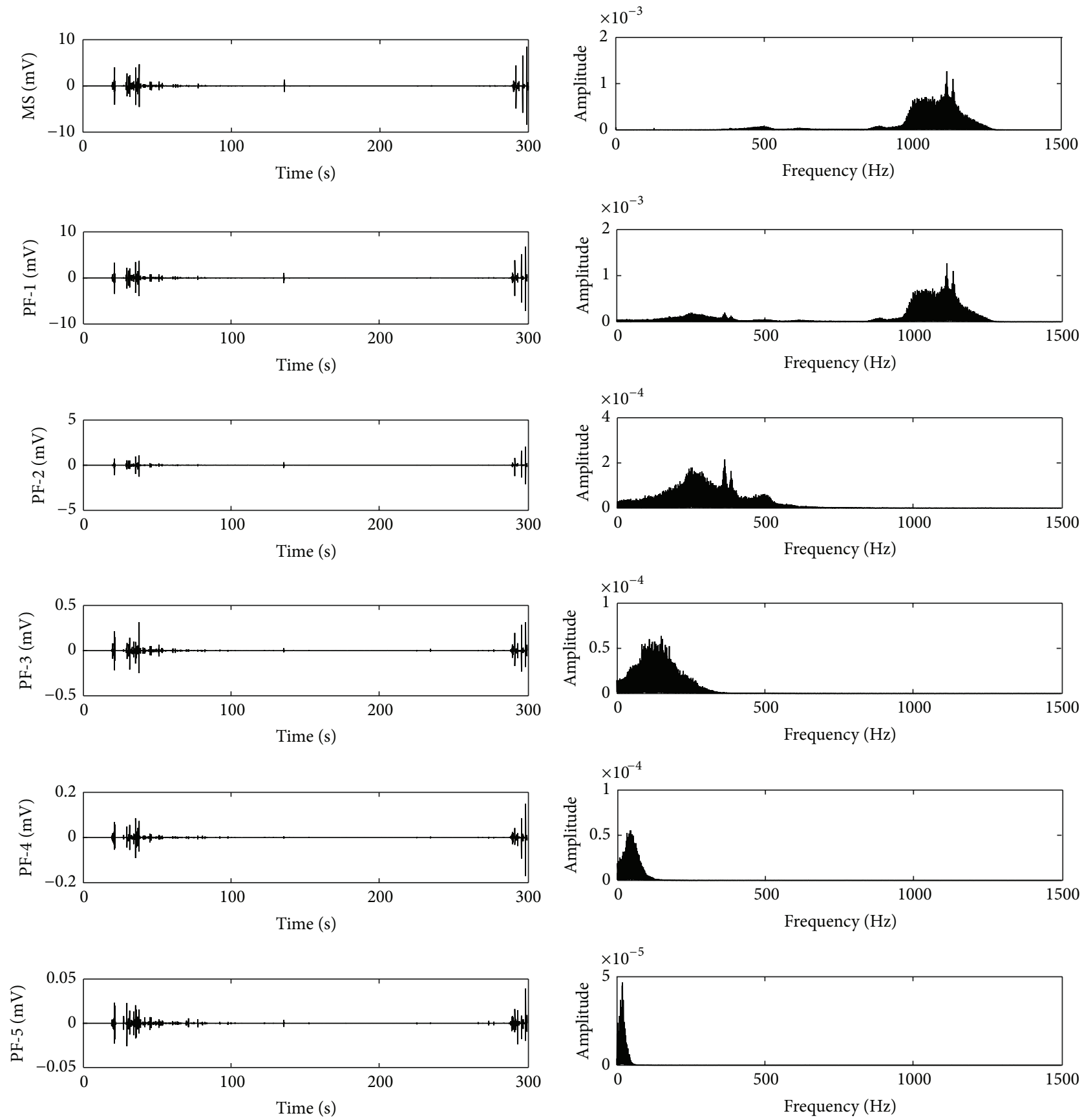

FIgURe 5: A typical LMD result of CSC2.

sections of typical MS events data of cement sample (CMSA1) and glass sample (GSB1) in early stage, middle stage, and poststage. In terms of cement specimen, the maximum amplitude of signal increases obviously with the loading stage, the real amplitude from $1 \mathrm{mV}$ in early stage to $20 \mathrm{mV}$ in the poststage, and relative amplitude of FFT from 0.01 to 0.04 . From the frequency domain point of view, before the coming of main fracture in poststage, the frequency of signal is mainly from 0 to $500 \mathrm{~Hz}$ with maximum frequency around $100-500 \mathrm{~Hz}$, while in the poststage the main frequency is from 1000 to $1500 \mathrm{~Hz}$. Also, it should be noticed that in every stage the MS signals all owned relatively wide frequency domain distribution. Analysis result of the same method on coal specimen is very similar to cement. However, for glass samples, the maximum amplitude is not in the poststage and the frequency distribution is also different. As shown in Figure 4, the MS events are detected in the whole loading process. Theoretically speaking, coal and cement samples were similarly made up of powders and couplant; to some extent, these two kinds of samples are homogeneous and isotropic, while glass samples are combination of several layers. This yields the difference of inter- or intragrain failure 


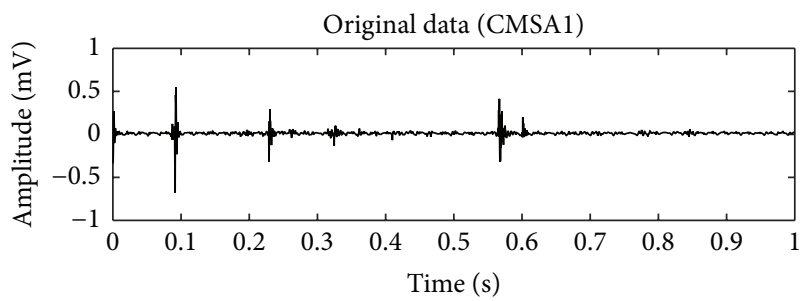

(a)

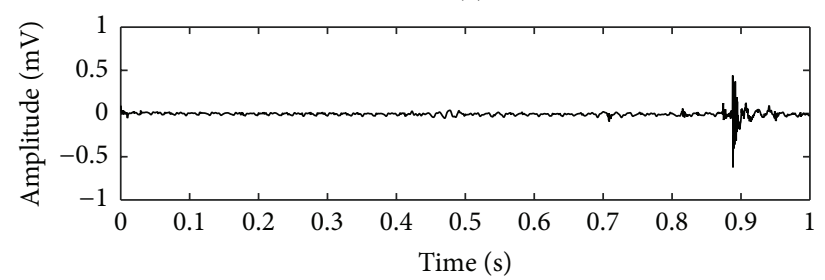

(b)

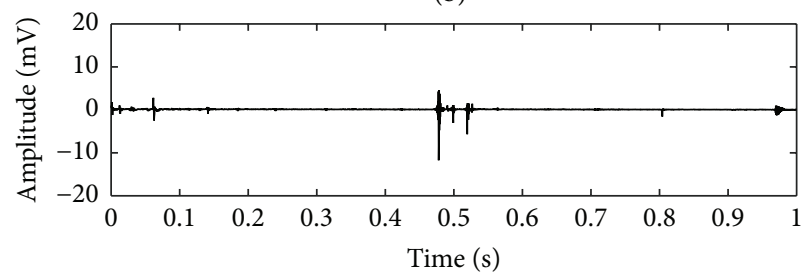

(c)

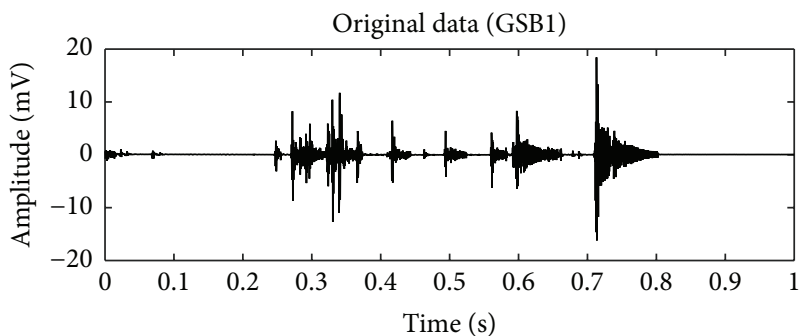

(a)

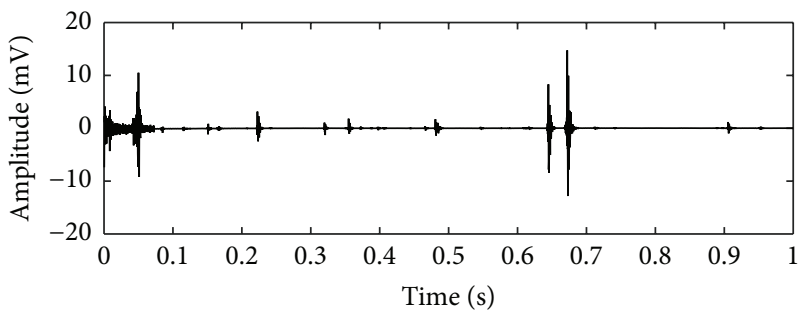

(b)

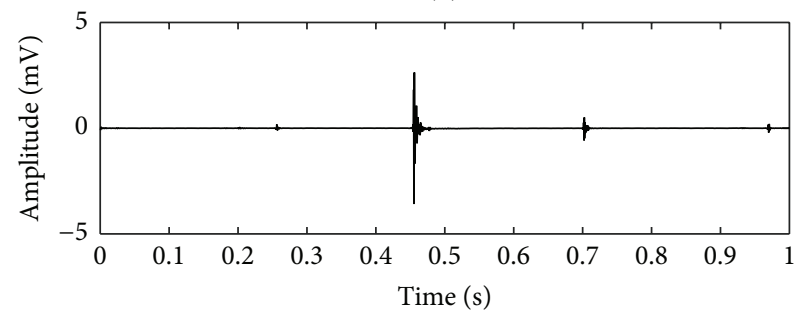

(c)

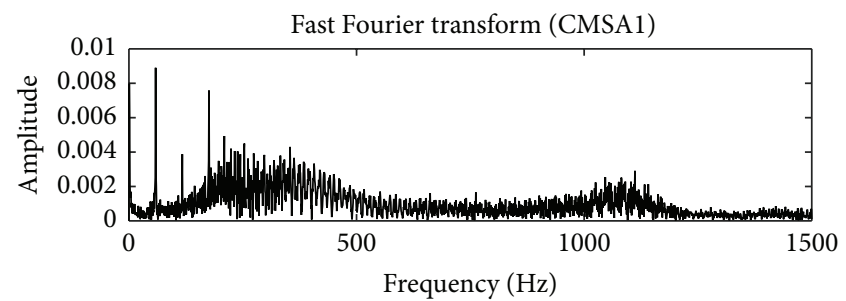

(a)

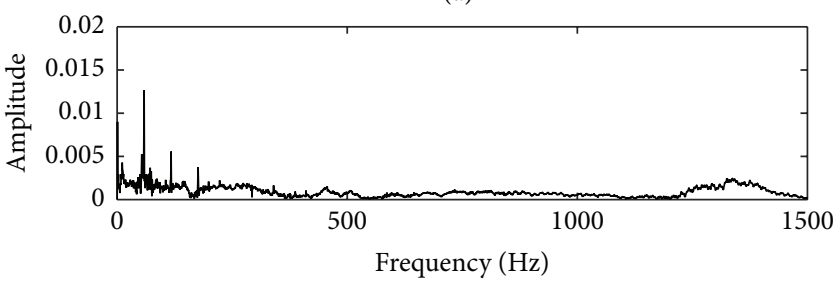

(b)

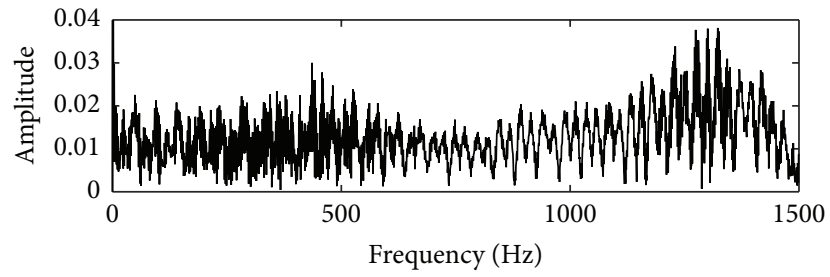

(c)

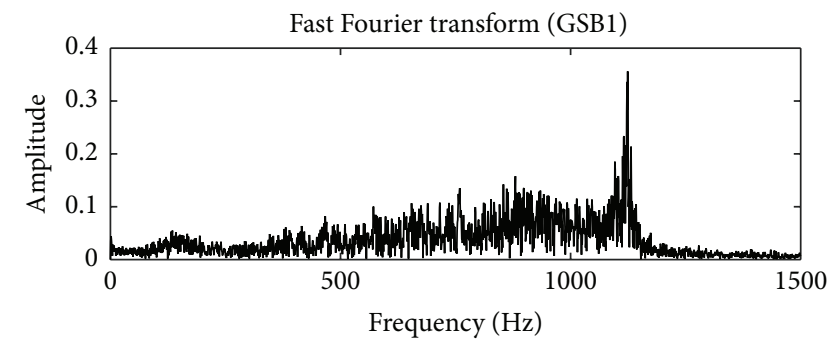

(a)

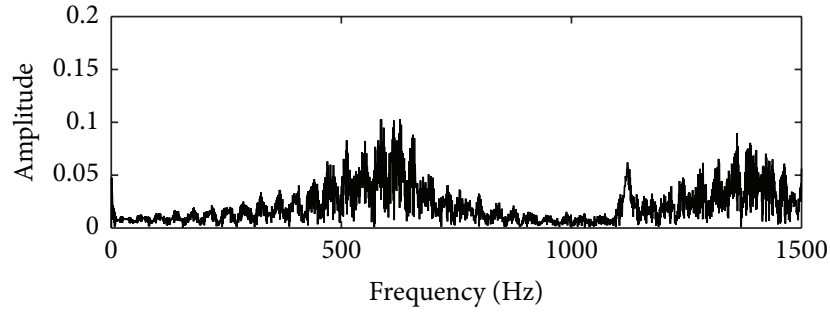

(b)

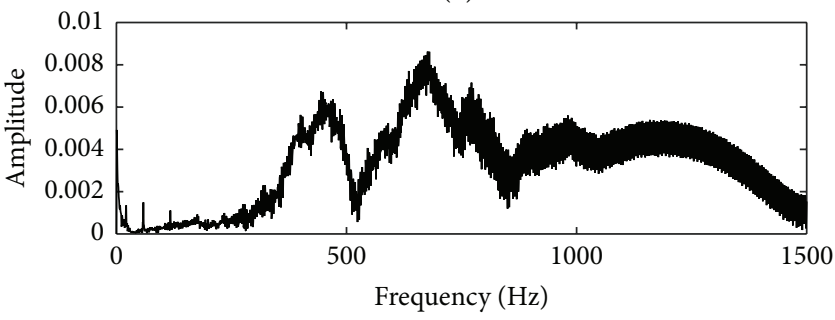

(c)

FiguRE 6: MS signal during cement and glass damage in different loading stages: (a) early stage; (b) middle stage; (c) poststage. 


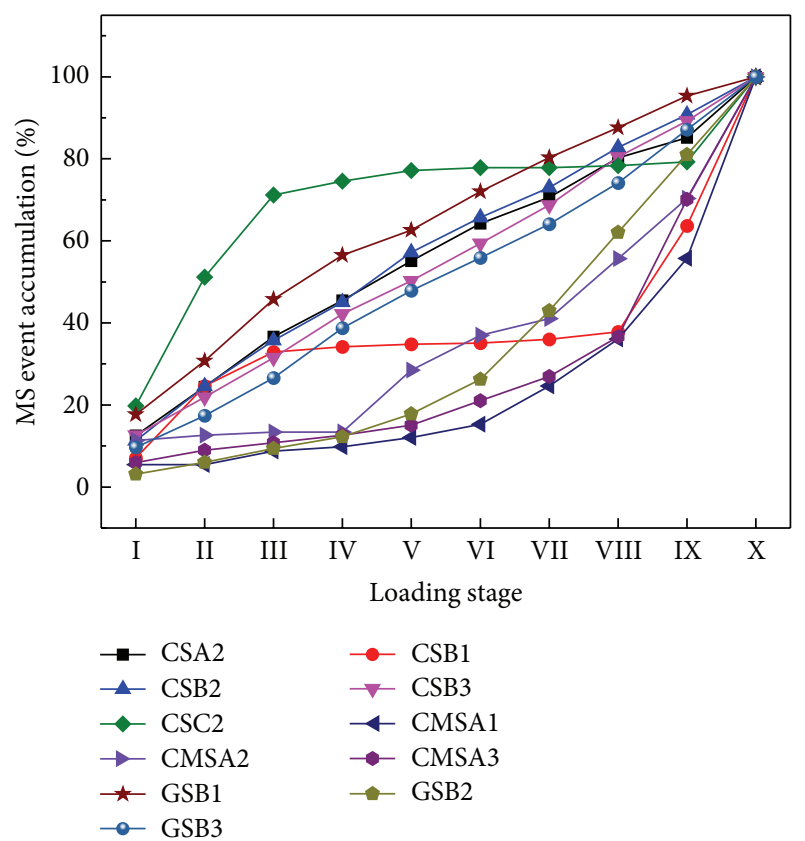

FIGURE 7: The event accumulation variation during the loading stage.

and the rule of crack or cleat initiation and propagation in the samples. Furthermore, the intrinsic resonant frequencies of variations of materials also contribute to the monitoring result.

5.2. MS Event Count and Event Rate. As mentioned above, we used the STA/LTA method to recognize effective MS event, counting the ring and event number. During the detection of effective MS signal, if the ratio of STA and LTA is over the threshold, the number counter of MS event and ring will be triggered, but the difference is that a single event will not stop until the value goes back to being under the threshold, while the ring number counts all single section over the critical amplitude. It can be seen from the study that the MS event and ring count are quite different for these three kinds of materials, and this shows irregular characteristics even in the same kind of material (Tables 2 and 3). An interesting phenomenon is that cement specimen procedures least MS event in comparison with coal and glass. However, as the loading time for each sample is quite different, the event rate value is quite similar for all the samples. The average event rate per second is around 2, but for cement sample like CMSA1 and CMSA3 it is only 0.25 and 0.22.

Figure 7 shows the total event accumulation ratio of the whole loading process. The variations tendencies are quite different for different sample, for one group of the samples (CSB2, CSA2, CSB3, GSB1, and GSB3) shows linear type of increase in the loading process, while for the other series of samples (CMSA1, GSB2, CMSA2, and CMSA3) event accumulation increases smoothly at first (stages I-V) and grows sharply after that (stages VI-X). These two types of tendencies give an illustration of MS activities in the whole

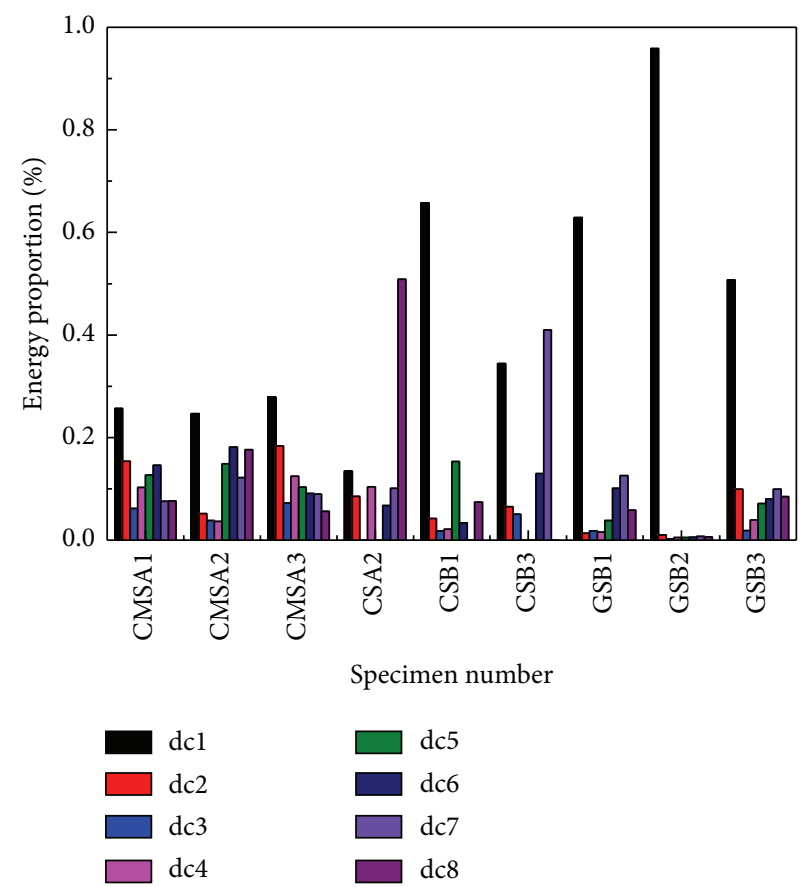

FIGURE 8: Energy proportion of WPT best tree decomposition.

process, and this phenomenon has great agreement with the stress and material damage rules.

5.3. The Energy Distribution Characteristics of MS Signal. The analysis on energy distribution of MS signal is based on result of WPT best tree transformation. It can be seen from Figure 1 that the signal is decomposed into 8 decompositions, denoted as $\mathrm{dcl}$ to $\mathrm{dc} 8$. According to the node number, the corresponding frequency bands of each node component are 0$46.9 \mathrm{~Hz}, 46.9-93.8 \mathrm{~Hz}, 93.8-140.6 \mathrm{~Hz}, 140.6-187.5 \mathrm{~Hz}, 187.5-$ $375.0 \mathrm{~Hz}, 375.0-750 \mathrm{~Hz}, 750-1078.1 \mathrm{~Hz}$, and $1078.1-1500 \mathrm{~Hz}$, respectively. Examples of several specimens in terms of energy distribution of the eight decompositions are shown in Figure 8. Hereby, the energy distribution analysis also shows the frequency-spectrum characteristics of different materials. It is obvious to see and conclude that all specimens made of different materials are abundant with low frequency components, especially for dcl. However, some differences between each material type could also be found. In the cases of glass specimens, the total signal energy for each specimen in $0-46.9 \mathrm{~Hz}$ is all more than $50 \%(62.9 \%, 95.8 \%$, and $50.7 \%)$. As glass is a kind of typical brittle material, there are always big fractures generated directly when it is compressed and deformed. This kind of rapid release of energy will limit the energy accumulation and the big fractures all limit the spreading of stress wave. Consequently, the signal energy is mainly from low frequency domain. By contrast, the energy proportions for cement produced signals are widely distributed in all frequency domains, mainly covering the 093.8 Hz and $140.6-750 \mathrm{~Hz}$. But, for coal, the situation is much more complicated. The main energy distribution domain for every sample seems to change greatly in their medium and 
TABLE 2: Ring count distribution and accumulation in different loading stage.

\begin{tabular}{lccccccccccc}
\hline Sample & I & II & III & IV & V & VI & VII & VIII & IX & X & Total \\
\hline CSA2 & 6367 & 7147 & 8068 & 5044 & 4966 & 4792 & 3178 & 4998 & 2793 & 11400 & 58753 \\
CSB1 & 194 & 1666 & 892 & 140 & 59 & 22 & 71 & 174 & 2399 & 4145 & 9762 \\
CSB2 & 1797 & 1938 & 1430 & 1264 & 1746 & 1117 & 814 & 1363 & 932 & 1570 & 13971 \\
CSB3 & 13174 & 6847 & 8510 & 8543 & 6849 & 7595 & 8019 & 10858 & 7705 & 9417 & 87517 \\
CSC2 & 1596 & 6451 & 3153 & 569 & 640 & 123 & 0 & 122 & 177 & 3259 & 16090 \\
CMSA1 & 630 & 57 & 43 & 0 & 905 & 567 & 238 & 686 & 707 & 1686 & 5519 \\
CMSA2 & 243 & 0 & 152 & 25 & 482 & 211 & 362 & 597 & 1146 & 2350 & 5568 \\
CMSA3 & 1652 & 325 & 199 & 175 & 667 & 1203 & 1563 & 3438 & 11684 & 11132 \\
GSB1 & 6961 & 5387 & 7107 & 4334 & 3437 & 4303 & 3160 & 2680 & 3460 & 1507 & 42038 \\
GSB2 & 2016 & 2521 & 2578 & 2613 & 3802 & 6703 & 17618 & 23977 & 23964 & 21802 & 107594 \\
GSB3 & 11958 & 9097 & 10882 & 16121 & 11292 & 9896 & 10314 & 11962 & 18636 & 17162 & 127320 \\
\hline
\end{tabular}

TABLE 3: MS event count distribution and accumulation in different loading stage.

\begin{tabular}{lcccccccccccc}
\hline Sample & I & II & III & IV & V & VI & VII & VIII & IX & X & Total & Event rate \\
\hline CSA2 & 311 & 294 & 302 & 219 & 239 & 226 & 159 & 238 & 121 & 368 & 2477 & 2.36 \\
CSB1 & 23 & 57 & 27 & 4 & 2 & 1 & 3 & 6 & 84 & 118 & 325 & 2.17 \\
CSB2 & 94 & 111 & 93 & 78 & 101 & 71 & 61 & 81 & 67 & 77 & 834 & 3.09 \\
CSB3 & 559 & 409 & 428 & 472 & 359 & 405 & 413 & 519 & 388 & 478 & 4430 & 2.42 \\
CSC2 & 83 & 132 & 84 & 14 & 11 & 3 & 0 & 2 & 4 & 87 & 420 & 1.4 \\
CMSA1 & 10 & 0 & 6 & 2 & 4 & 6 & 17 & 21 & 36 & 81 & 183 \\
CMSA2 & 28 & 3 & 2 & 0 & 37 & 21 & 10 & 36 & 36 & 73 & 246 & 0.22 \\
CMSA3 & 66 & 34 & 20 & 21 & 27 & 67 & 66 & 108 & 374 & 333 & 1116 \\
GSB1 & 220 & 162 & 187 & 133 & 76 & 117 & 103 & 91 & 96 & 58 & 1243 \\
GSB2 & 100 & 92 & 107 & 90 & 176 & 268 & 531 & 609 & 602 & 603 & 3178 & 1.3 \\
GSB3 & 401 & 323 & 382 & 505 & 378 & 335 & 342 & 417 & 540 & 535 & 4158 & 2.43 \\
\hline
\end{tabular}

high frequency components. Specifically, CSA2 has more frequency components for $\mathrm{d} 8$, and CSB1 has more for $\mathrm{d} 5$, while CSB3 is abundant with $\mathrm{d} 7$. This may be mainly because of the differences for loading rate and coal powder sizes and of course the boundaries and interfaces inside the samples.

5.4. Relationship between MS Signal and Loading Rate. To analyze the microseismic characteristics of different materials, different loading rate is set in the process of experiment. As mentioned above, coal, cement paste, and glass specimens have quite different mechanic strength and material characteristics. Thus, we set different loading rate variation for each type of materials: for coal it is $5-20 \mathrm{~N} / \mathrm{s}$ and for cement and glass it is $150-300 \mathrm{~N} / \mathrm{s}$. Taking coal samples as an example, the statistics on CSB1, CSB2, and CSB3 show that the loading peak force values increase as the loading rate set larger, and the bigger the loading rate, the more the MS events and ring number activities recoded. The figure for this is 9762 and 13971 to 87517 in ring number and 325,834 to 4430 in MS single event. Furthermore, similar result for cement and glass sample can be found regarding the variation of loading rate. We believe that this is because MS phenomenon is actually kind of stress wave and release of energy, and larger loading speed results in more rapid energy accumulating and releasing out. Thus, there are more MS events and ring counts were founded during the whole loading process.

5.5. Relationship between MS Signal and Coal Powder Particle Size. A group of coal specimens (CSA2, CSB2, and CSC2) is selected to analyze the effect of coal powder size on MS characteristics. As shown in Table 1, under the same loading rate $(10 \mathrm{~N} / \mathrm{s})$, the peak values are $7.74 \mathrm{kN}, 2.72 \mathrm{kN}$, and $3.18 \mathrm{kN}$ for specimens made by particles size in $0-0.25 \mathrm{~mm}, 0.25-$ $0.5 \mathrm{~mm}$, and $0.5-2 \mathrm{~mm}$. Theoretically, the smaller the size of powders used is, the larger the strength of pressured briquette samples should be, for small particles could bond well. Although CSB2, which was made up of $0.25-0.5 \mathrm{~mm}$ particle size powders, only got $2.72 \mathrm{kN}$ loading peak value before the primary damage, the general trend between CSA2 and CSC2 showed an obvious decrease of sample strength with powder size going up. As bigger strength means more loading time, it is not surprising that more MS events were recorded for CSA2 and CSC2 (Table 2). On the contrary, CSB2 has the largest event rate, and it is 3.09 events every second as shown in Table 3. Another feature by which powder size will influence the man-made specimen structure is the homogeneity. This is because specimens made by larger particle size of powder have more cracks inside. As a result, it will take longer time 
during the crack closure stage and finally get into linear elastic stage. Also, as shown in Figure 7, the curves of MS event accumulation with loading stage for CSA2 and CSB2 increase more linearly, while for CSC2 made by largest powder it is quite different. In summary, although the loading time, specimen strength, and events statistic for CSB2 show some abnormality compared with general trend from small powder size to large powder size made specimen, the global event accumulation has great consistency with theoretical analysis.

\section{Conclusion}

A total of 11 experiment tests on coal, cement paste, and glass specimens were carried out under uniaxial compression condition. Coal powder particle size, material type, and loading rate are selected to compare and analyze MS/AE characteristic. In the meantime, the MS event rate, accumulated ringing number, relationship between loading stress and MS event, energy distribution, and frequency-time characteristics of MS signal produced during the damage of different specimens were also discussed in the work.

To separate the MS signal from the noises polluted signals, the combination of wavelet packet transform (WPT) and local mean decomposition (LMD) method was chosen to denoise and analyze all the signals collected. The application of this new method proved that the WPT-LMD method had a good performance in denoising and filtering the MS data, and it also could be used as common tool in the issues of frequency-spectrum characteristics analysis of MS signal or MS-like nonstationary and nonlinear signal.

The investigation result on the MS signal features of three categories of materials showed the following:

(1) In terms of the damage and deformation of coal and cement, in the early stage few effective signals are produced; then specimens will experience a relative clam middle stage, and, in the poststage, where main rupture occurred, a large number of MS events were recorded. But, for glass samples, the MS event generations were throughout the whole loading process. We conclude that this is because of the brittle and crispy features of glass material, which means less energy stored and quickly released.

(2) Also, there is good corresponding relation between loading time and MS events and ring numbers; the longer loading time is, the more MS events and ring numbers are detected, while for loading rate there is no obvious effect on MS.

(3) In the case of relationship for coal powder particle size and MS feature, we found that the MS accumulation patterns of small particles $(0-0.5 \mathrm{~mm})$ made specimens be more linear, while large particles (0.5-2 $\mathrm{mm})$ made specimens own typical nonlinear characteristics. The latter will spend much more time to close the crack and be crushed into small powders. There seems to be a decrease trend of specimen strengths with the powder size used from small to large, but there is abnormal case of CSB2. Similar conclusion could be made for event and ring number counts and event rate; this may be caused by a failure of specimen preparation, and this is supposed to be examined in the further study.

(4) From the frequency-spectrum point of view, all tests on different materials showed wide frequency domain characteristics, which are fallen in the domain of $0-200 \mathrm{~Hz}, 300-500 \mathrm{~Hz}$, and $1000-1500 \mathrm{~Hz}$. However, it should be noted that the frequency domain of glass specimens is mainly concentrated in the low frequency $(0-93.8 \mathrm{~Hz})$, due to their extremely brittle mechanical characteristics.

To sum up, we believe that the outcome of the paper will be of great significance to improve the dynamic disasters forecast and improve coal mining safety. This may embody some promotions in data processing by using the WPT-LMD method and provide a theoretical basis for understanding the mechanism of MS activities due to the experimental phenomenon and conclusions presented.

\section{Conflict of Interests}

The authors declare that there is no conflict of interests regarding the publication of this paper.

\section{Acknowledgments}

This study was supported by National Natural Science Foundation of China (Grant no. 51274206). The corresponding author also acknowledged the financial support provided by Chinese Scholarship Council (CSC).

\section{References}

[1] C. U. Grosse and M. Ohtsu, Acoustic Emission Testing, Springer, Berlin, Germany, 2008.

[2] H. R. Hardy Jr., Acoustic Emission/Microseismic Activity: Volume 1: Principles, Techniques and Geotechnical Applications, CRC Press, 2005.

[3] C.-P. Lu, L.-M. Dou, B. Liu, Y.-S. Xie, and H.-S. Liu, "Microseismic low-frequency precursor effect of bursting failure of coal and rock," Journal of Applied Geophysics, vol. 79, pp. 55-63, 2012.

[4] C.-P. Lu, L.-M. Dou, H. Liu, H.-S. Liu, B. Liu, and B.-B. Du, "Case study on microseismic effect of coal and gas outburst process," International Journal of Rock Mechanics and Mining Sciences, vol. 53, pp. 101-110, 2012.

[5] S. I. Qin, J. Cheng, and S. Zhu, "The application and prospect of microseismic technique in coalmine," Procedia Environmental Sciences, vol. 12, pp. 218-224, 2012.

[6] X. H. Liu, C. X. Liu, S. Zhuang, L. Wang, and S. S. Lin, "Laboratory studies on acoustic emission characteristics to coal dynamic response under variable accelerative load," Applied Mechanics and Materials, vol. 580-583, pp. 623-627, 2014.

[7] N. Cook, "The seismic location of rockbursts," in Proceedings of the 5th Rock Mechanics Symposium, pp. 463-516, 1963.

[8] A. G. Beattie, "Acoustic emission, principles and instrumentation," Journal of Acoustic Emission, vol. 2, no. 12, pp. 95-128, 1983. 
[9] L. Obert, "The microseismic method: discovery and early history," in Proceedings of the 1st Conference on Acoustic Emission/Microseismic Activity in Geologic Structures and Materials, pp. 11-12, 1977.

[10] I. Yamada, K. Masuda, and H. Mizutani, "Electromagnetic and acoustic emission associated with rock fracture," Physics of the Earth and Planetary Interiors, vol. 57, no. 1-2, pp. 157-168, 1989.

[11] C.-P. Lu, L.-M. Dou, N. Zhang et al., "Microseismic frequencyspectrum evolutionary rule of rockburst triggered by roof fall," International Journal of Rock Mechanics and Mining Sciences, vol. 64, pp. 6-16, 2013.

[12] S. Sasaki, "Characteristics of microseismic events induced during hydraulic fracturing experiments at the Hijiori hot dry rock geothermal energy site, Yamagata, Japan," Tectonophysics, vol. 289, no. 1-3, pp. 171-188, 1998.

[13] F. Spaepen, "A microscopic mechanism for steady state inhomogeneous flow in metallic glasses," Acta Metallurgica, vol. 25, no. 4, pp. 407-415, 1977.

[14] P. E. Tikkanen, "Nonlinear wavelet and wavelet packet denoising of electrocardiogram signal," Biological Cybernetics, vol. 80, no. 4, pp. 259-267, 1999.

[15] O. A. M. Aly, A. S. Omar, and A. Z. Elsherbeni, "Detection and localization of RF radar pulses in noise environments using wavelet packet transform and higher order statistics," Progress in Electromagnetics Research, vol. 58, pp. 301-317, 2006.

[16] A. Kyprianou, P. L. Lewin, V. Efthimiou, A. Stavrou, and G. E. Georghiou, "Wavelet packet denoising for online partial discharge detection in cables and its application to experimental field results," Measurement Science and Technology, vol. 17, no. 9, pp. 2367-2379, 2006.

[17] J. S. Smith, "The local mean decomposition and its application to EEG perception data," Journal of the Royal Society Interface, vol. 2, no. 5, pp. 443-454, 2005.

[18] Z. Sun and C. C. Chang, "Structural damage assessment based on wavelet packet transform," Journal of Structural Engineering, vol. 128, no. 10, pp. 1354-1361, 2002.

[19] J.-D. Wu and C.-H. Liu, "An expert system for fault diagnosis in internal combustion engines using wavelet packet transform and neural network," Expert Systems with Applications, vol. 36, no. 3, pp. 4278-4286, 2009.

[20] Y. Wang, Z. He, and Y. Zi, "A demodulation method based on improved local mean decomposition and its application in rubimpact fault diagnosis," Measurement Science and Technology, vol. 20, no. 2, Article ID 025704, 2009.

[21] Y. Wang, Z. He, and Y. Zi, "A comparative study on the local mean decomposition and empirical mode decomposition and their applications to rotating machinery health diagnosis," Journal of Vibration and Acoustics, vol. 132, no. 2, Article ID 021010, 2010.

[22] A. Trnkoczy, "Understanding and parameter setting of STA/LTA trigger algorithm," in IASPEI New Manual of Seismological Observatory Practice, vol. 2, pp. 1-19, Deutsches GeoForschungsZentrum GFZ, Potsdam, Germany, 2002.

[23] V. Vishal, P. G. Ranjith, and T. N. Singh, "An experimental investigation on behaviour of coal under fluid saturation, using acoustic emission," Journal of Natural Gas Science and Engineering, vol. 22, pp. 428-436, 2015. 


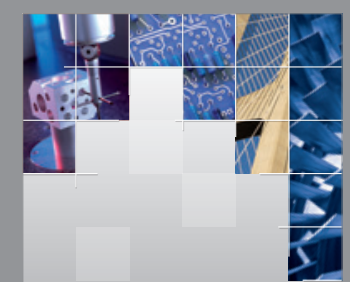

\section{Enfincering}
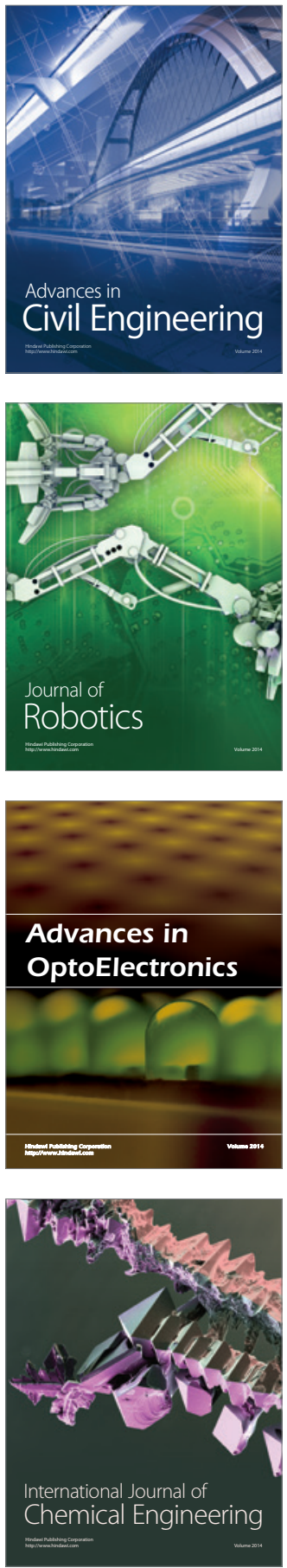

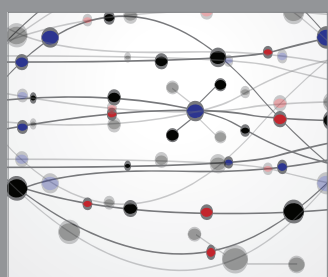

The Scientific World Journal

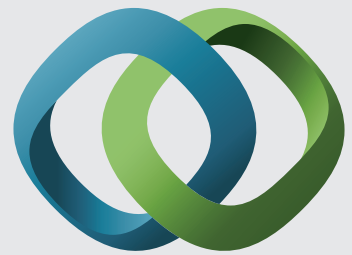

\section{Hindawi}

Submit your manuscripts at

http://www.hindawi.com
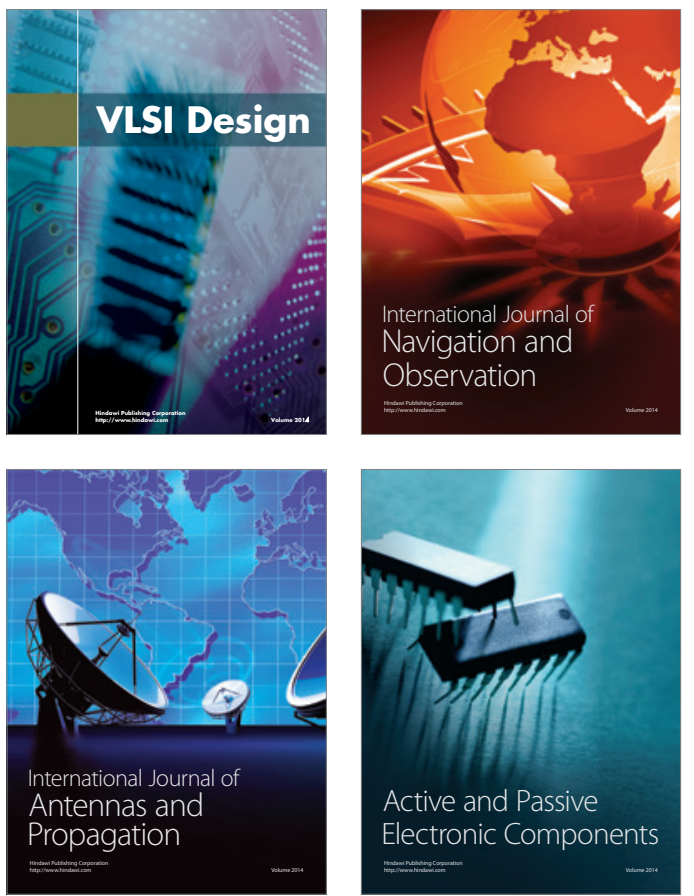
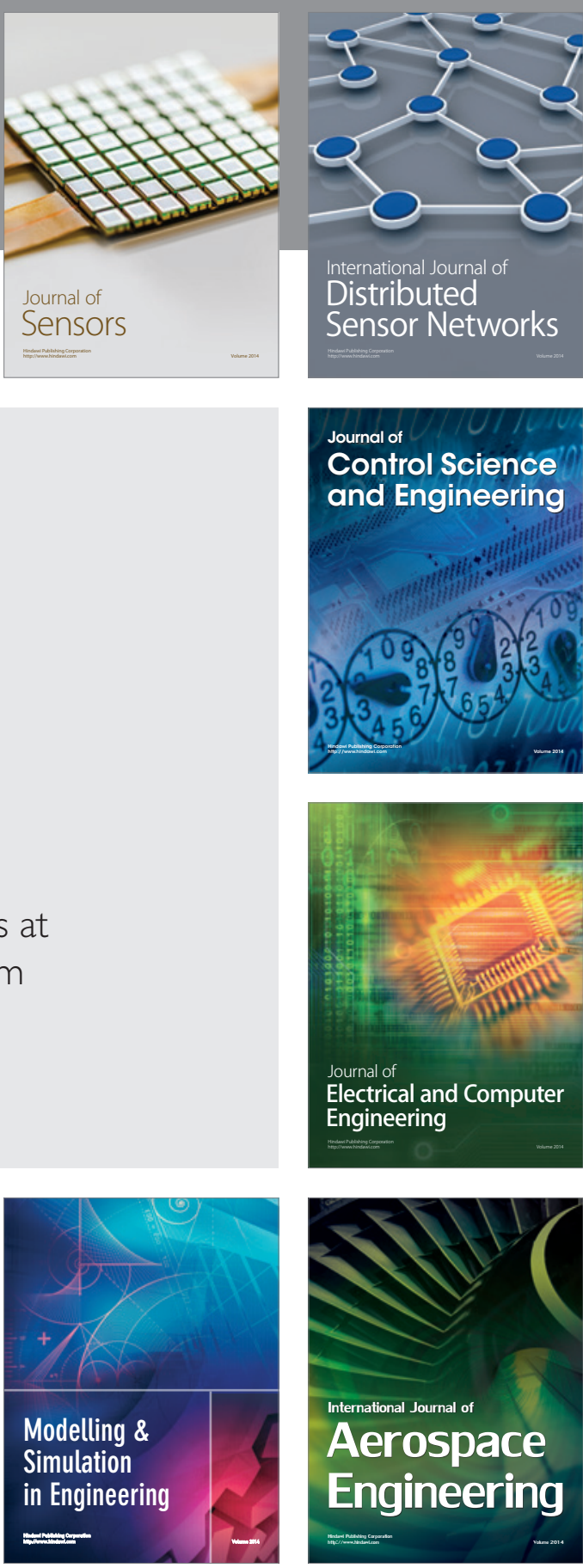

International Journal of

Distributed

Sensor Networks

Journal of

Control Science

and Engineering
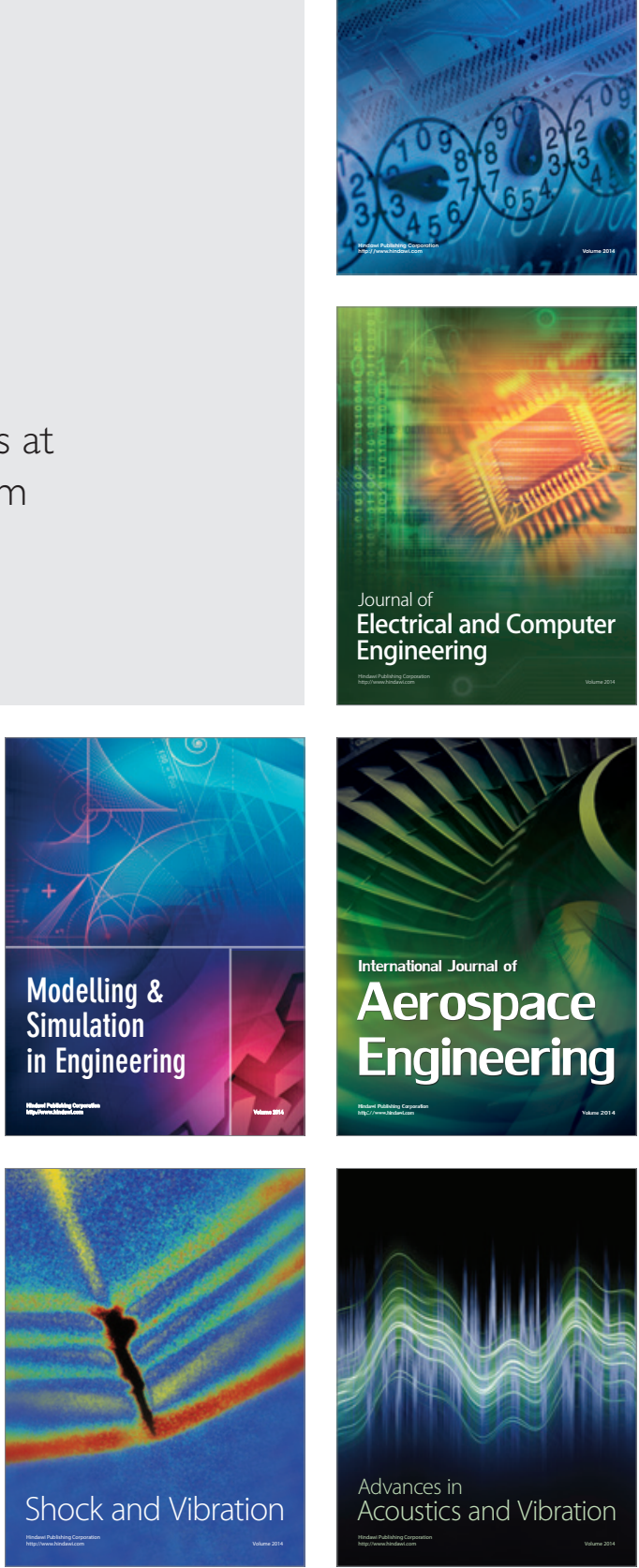